Check for updates

Cite this: RSC Adv., 2017, 7, 32236

\title{
In situ inorganic flame retardant modified hemp and its polypropylene composites
}

\author{
W. J. Zhao, ${ }^{a}$ Q. X. Hu, ${ }^{a}$ N. N. Zhang, ${ }^{a}$ Y. C. Wei, ${ }^{a}$ Q. Zhao, ${ }^{a}$ Y. M. Zhang, ${ }^{a}$ J. B. Dong, ${ }^{a}$ \\ Z. Y. Sun, ${ }^{b}$ B. J. Liu, ${ }^{c}$ L. Lid and W. Hu (iD *a
}

A hemp-reinforced polypropylene (PP) composite with excellent flame retarding and mechanical properties was prepared with the melt blending method. Hemp fiber ( $F$ ) was first simply in situ modified with an inorganic salt solution, which was prepared by mixing $4.32 \%$ sodium hydrate $(\mathrm{NaOH})$ and $6 \%$ calcium chloride $\left(\mathrm{CaCl}_{2}\right)$ at room temperature for $0.5 \mathrm{~h}$. The modified hemp (F1) was proved to be modified by the calcium salt through Fourier-transform infrared and scanning electron microscopy (SEM) measurements. The thermal stability, mechanical, and flame retarding properties of the composites were studied by thermogravimetric analysis, mechanical tests, and limiting oxygen index (LOI) measurements, respectively. The LOI of the composites with $50 \%$ of F1 and $15 \%$ poly(phosphoric acid amine) reached $25.5 \%$, which was much higher than that of PP (18.5\%). The tensile strength of the composite with $50 \%$ of F1 was $38 \%$ higher than that of PP (24 MPa). The composite interface between the F1 and PP matrix was investigated by SEM, and was shown to be significantly improved. This showed that in situ inorganic modification of hemp with a mixture of $\mathrm{NaOH}$ and $\mathrm{CaCl}_{2}$ is a promising method to improve both the flame retarding and mechanical properties of the biocomposite.

Received 10th April 2017

Accepted 13th June 2017

DOI: $10.1039 / \mathrm{c} 7 \mathrm{ra0} 4078 \mathrm{~d}$

rsc.li/rsc-advances composites can be improved by adding a flame retardant into the composites. ${ }^{12}$ Reports were found on the application of intumescent ammonium polyphosphate (APP) on kenaf natural fiber/polypropylene (PP) composite. ${ }^{\mathbf{1 3 , 1 4}}$ Inorganic hydroxides, such as $\mathrm{Mg}(\mathrm{OH})_{2}$ and $\mathrm{Al}(\mathrm{OH})_{3}$, could also be applied as flame retardant for composites. ${ }^{15} \mathrm{Mg}(\mathrm{OH})_{2}$ was applied to improve the flammability of the sisal/PP composite. ${ }^{6}$ It was also directly incorporated into sawdust/PP composites. Consequently, the burning rate of the composite with $25 \% \mathrm{Mg}(\mathrm{OH})_{2}$ decreased by $34.7 \%$ compared with that of pure PP. ${ }^{16}$ However, the mechanical properties of the composites decreased when the flame retardants were added.

On the other hand, the hydrophilic surface of the natural fiber results in its bad interfacial property with the hydrophobic matrix, such as polyolefin. The bad interface leads to the decreased mechanical properties of the composites. ${ }^{10,17} \mathrm{Chem}-$ ical modification and coupling agents are effective methods to transform natural fiber from hydrophilic into hydrophobic. ${ }^{\mathbf{1 7 , 1 8}}$ Moreover, alkali treatment is always applied first to remove the impurities, lignin, and hemicellulose on the fiber surface, which exposes more hydroxyl groups for further modification. Also, alkali could react with the hydroxyl group, and thereafter negative oxygen ion can be produced. ${ }^{19}$ Among the coupling agents, maleic-grafted polypropylene (MAPP) is very efficient in improving the interfacial property of natural fiber-reinforced composites with approximately $2 \%$ added in the system. ${ }^{20}$

So far, few reports exist about another cheap alkaline-earth metal hydroxide, calcium hydroxide $\left(\mathrm{Ca}(\mathrm{OH})_{2}\right)$, which could

${ }^{d}$ School of Life Science and Technology, Harbin Institute of Technology, Harbin, 150080, P. R. China 
also function as a flame retardant. When $\mathrm{Ca}(\mathrm{OH})_{2}$ is heated, it is decomposed into calcium oxide $(\mathrm{CaO})$ and water. The water and $\mathrm{CaO}$ can help to stop the flame during firing. ${ }^{21} \mathrm{This}$ reaction and mechanism are similar to those related to $\mathrm{Mg}(\mathrm{OH})_{2}$ and $\mathrm{Al}(\mathrm{OH})_{3} \cdot{ }^{22,23}$ As the inorganic fire retardant material, $\mathrm{Mg}(\mathrm{OH})_{2}$ and $\mathrm{Al}(\mathrm{OH})_{3}$ are relatively not cheap because usually at least $25 \%$ of them are necessary to be applied for the satisfied fire retardant effect for the composites. In addition, the composite mechanical properties are always affected obviously after their insertion.

Given that the direct insertion of flame retardant into composites usually decreases the composite mechanical properties, in this work, the hemp was modified with the freshly prepared $\mathrm{Ca}(\mathrm{OH})_{2}$ emulsion. The preparation method of $\mathrm{Ca}(\mathrm{OH})_{2}$ emulsion was to mix the molar-equivalent alkali $(\mathrm{NaOH})$ and calcium chloride $\left(\mathrm{CaCl}_{2}\right)$ solution. The modified hemp and its composites were characterized, and the synergistic effect of the inorganic modification with the coupling agent MAPP and the flame retardant APP was also examined. The study afforded a new promising modification method on hemp to improve both flame retarding and mechanical properties of the biocomposites.

\section{Experimental}

\section{Materials}

Hemp was received from Youma Company of Shandong Province, China. $\mathrm{NaOH}(98 \%), \mathrm{CaCl}_{2}(98 \%)$ was obtained from Tianjin Zhiyuan Chemical Reagent Co., Ltd. Polypropylene (PP1274) was received from Yang Rong Plastic raw material Co., Ltd of Guangdong Province, China. MAPP 7452 was received from Clariant, Germany. APP was received from Shandong Shian chemical Co., Ltd.

Hemp was cut into $3 \mathrm{~mm}$ of length. The obtained short fibers were washed with distilled water, and then were dried at room temperature for $8 \mathrm{~h}$, and further oven dried at $120{ }^{\circ} \mathrm{C}$ for another $3 \mathrm{~h}$. The fully dried fibers were stored in sealed plastic bag.

\section{In situ inorganic treatment of hemp fiber}

Mixing 4.32\% NaOH (2.16 g, $0.054 \mathrm{~mol})$ solution of $50 \mathrm{ml}$ with $6 \% \mathrm{CaCl}_{2}(3 \mathrm{~g}, 0.027 \mathrm{~mol})$ solution of $50 \mathrm{ml}$, respectively, to get a $2 \% \mathrm{Ca}(\mathrm{OH})_{2}(2 \mathrm{~g}, 0.027 \mathrm{~mol})$ emulsion of $100 \mathrm{ml}$, in the light that $2 \mathrm{~mol} \mathrm{NaOH}$ reacts with $1 \mathrm{~mol} \mathrm{CaCl}_{2}$ to get $\left.1 \mathrm{~mol} \mathrm{Ca(OH}\right)_{2}$. The short hemp fiber of $10 \mathrm{~g}$ were immersed and soaked into $100 \mathrm{ml}$ of such emulsion at room temperature as soon as possible, and then kept for $0.5 \mathrm{~h}$ with stirring. Thereafter, the treated fiber was washed with distilled water twice to remove the attached $\mathrm{Ca}(\mathrm{OH})_{2}$, and dried at room temperature for $8 \mathrm{~h}$, and further oven dried at $120^{\circ} \mathrm{C}$ for $3 \mathrm{~h}$ to remove all the moisture in the fiber.

\section{Preparation of thermal degraded hemp residue}

The thermal degradation residue of the untreated and treated hemp fibers was prepared with a CQ-GS 10A pipe furnace from Luoyang Chunqing Furnace Industry Co., Ltd (Luoyang, China).
The samples of $\mathrm{F}$ and $\mathrm{F} 1$ were initially heated from $50{ }^{\circ} \mathrm{C}$ to $300{ }^{\circ} \mathrm{C}$ or $500{ }^{\circ} \mathrm{C}$ with a heating rate of $10^{\circ} \mathrm{C} \mathrm{min}{ }^{-1}$ and kept at $300^{\circ} \mathrm{C}$ or $500^{\circ} \mathrm{C}$ for $1 \mathrm{~h} . \mathrm{N}_{2}$ was flowed during the measurement. The thermal degradation residue of the untreated and treated hemp fibers treated at $300{ }^{\circ} \mathrm{C}$ were denoted as $300 \mathrm{~F}$ and $300 \mathrm{~F} 1$, respectively, and 500F and 500F1, respectively, for the materials treated at $500{ }^{\circ} \mathrm{C}$. The chemical structure, surface morphology and crystallization were analyzed with FTIR, SEM and XRD measurement.

\section{Preparation of hemp/PP composites}

The hemp fiber, PP, APP and MAPP were oven dried at $80^{\circ} \mathrm{C}$ for $12 \mathrm{~h}$. They were mixed together in a plastic bag, and the bag was sealed tightly. The materials were then compounded using HAAKE mixer (PolyLab OS RheoDrive 7) with a speed of $60 \mathrm{rpm}$ at $185{ }^{\circ} \mathrm{C}$ for $10 \mathrm{~min}$. The formulation of the composites was listed in Table 1 . The panel of composites was prepared by hot press at $185^{\circ} \mathrm{C}$ for $3 \mathrm{~min}$. The specimens for the mechanical test were taken from the panel.

\section{Characterization}

FTIR characterization. FTIR characterization of the untreated and treated fibers was performed with a Nicolet AVATAR-360 (USA) FTIR spectrometer by compressing samples on the stage in Attenuated Total Reflectance (ATR) transmittance mode in the wavenumber range of $4000-650 \mathrm{~cm}^{-1}$. The frequency was 32 and the scan number was 256 .

Fire resistance measurement. The oxygen index of the hemp fiber was measured according to the standard GB/T 5454-1997. LOI of the composites was obtained based on the standard ASTM D2863. The size of the specimens used for the flame retardant test was $100 \mathrm{~mm} \times 6.5 \mathrm{~mm} \times 3 \mathrm{~mm}$. A Qingdao ShanFang M606B oxygen index apparatus was applied for the measurement. UL-94 vertical burning level was tested on a CZF2 instrument (Jiangning, China) according to ASTM D 3801. The dimension of samples was $130 \mathrm{~mm} \times 13 \mathrm{~mm} \times 3.2 \mathrm{~mm}$.

Table 1 Formulation of the composites ${ }^{a}$

\begin{tabular}{llllll}
\hline Samples & PP $(\mathrm{g})$ & F1 $(\mathrm{g})$ & F $(\mathrm{g})$ & MAPP $(\mathrm{g})$ & APP $(\mathrm{g})$ \\
\hline PP & 100 & - & - & - & - \\
PPF-20 & 78 & - & 20 & 2 & - \\
PPF1-20 & 78 & 20 & - & 2 & - \\
PPF1-20-15R & 63 & 20 & - & 2 & 15 \\
PPF-30 & 68 & - & 30 & 2 & - \\
PPF1-30 & 68 & 30 & - & 2 & - \\
PPF1-30-10R & 58 & 30 & - & 2 & 10 \\
PPF1-30-15R & 53 & 30 & - & 2 & 15 \\
PPF1-30-20R & 48 & 30 & - & 2 & 20 \\
PPF-50 & 48 & - & 50 & 2 & - \\
PPF1-50 & 48 & 50 & - & 2 & - \\
PPF1-50-10R & 38 & 50 & - & 2 & 10 \\
PPF1-50-15R & 33 & 50 & - & 2 & 15 \\
PPF1-50-20R & 28 & 50 & - & 2 & 20
\end{tabular}

${ }^{a}$ And at least five notched specimens were tested to obtain the average values. 
Mechanical properties. The tensile strength and modulus of the PP and composites were measured according to ASTM D638 standard with a 3365 Instron universal tensile testing machine. Specimens were prepared according to the same standard. Crosshead speed was set as $1 \mathrm{~mm} \mathrm{~min}^{-1}$. At least five specimens were tested to obtain the average values.

According to the GB 1451-83 standard, the impact testing was carried out with a XJU-22 test machine from Chengde material testing machine manufacturing plant, china. Specimens were prepared according to the same standard.

Interface morphology characterization. Scanning electron microscopy (JSM5600) was used to determine the morphology of $\mathrm{F}$ and $\mathrm{F} 1$, their thermal degradation residue, and the fractured surface of PP composites after broken in the liquid nitrogen. The specimens were coated with gold, which rendered them conductive to be scanned under the electron beam.

Thermal stability. Perkins-Elmer TGA thermal gravimetric analyzer was applied to characterize the thermal property of PP and hemp/PP composites with a heating rate of $20{ }^{\circ} \mathrm{C} \mathrm{min}{ }^{-1}$ from $25{ }^{\circ} \mathrm{C}$ to $600{ }^{\circ} \mathrm{C} . \mathrm{N}_{2}$ was flowed during the measurement.

Crystallization behaviour. Crystallization properties of the PP and composites were analyzed applying DSC1 Star System from Mettler Toledo Instruments, Swiss. The samples were initially heated from 25 to $210{ }^{\circ} \mathrm{C}$ with a heating rate of $20^{\circ} \mathrm{C}$ $\min ^{-1}$, then cooled down to $25^{\circ} \mathrm{C}$ with a cooling rate of $10{ }^{\circ} \mathrm{C}$ $\min ^{-1}$, finally reheated to $210{ }^{\circ} \mathrm{C}$ with a heating rate of $10{ }^{\circ} \mathrm{C}$ $\min ^{-1} \cdot \mathrm{N}_{2}$ was flowed during the whole measurement.

The degree of crystallizations was determined as follows:

$$
X_{\mathrm{c}}=\left(\Delta H_{\mathrm{m}} /\left(w \times \Delta H_{\mathrm{m}}^{0}\right)\right) \times 100 \%
$$

where $\Delta H_{\mathrm{m}}$ is the experimental melting enthalpy $\left(\mathrm{J} \mathrm{g}^{-1}\right)$ and $\Delta H_{\mathrm{m}}^{0}$ is the melting enthalpy of a pure crystalline matrix, PP (209 $\left.\mathrm{J} \mathrm{g}^{-1}\right) .{ }^{24} w$ is the mass fraction of PP in the composite.

The crystallization behavior of PP, PP composites, and the thermal degradation residue 500F and 500F1 was measured with X-ray diffractometer D8 ADVANCE from BRUKER company (Germany). The samples were scanned in the angle range from $5^{\circ}$ to $60^{\circ}$. The scanning speed was $2^{\circ} \mathrm{min}^{-1}$.

\section{Results and discussion}

\section{Modification effect on hemp}

Fourier-transform infrared characterization. Fig. 1 shows Fourier-transform infrared (FTIR) spectra of hemp fiber (F) and the treated fiber (F1). And Fig. 1(b) is the magnification figure of $800-2000 \mathrm{~cm}^{-1}$ region in the FTIR spectra to show more clearly the absorption peaks in this region. The peak at $1425 \mathrm{~cm}^{-1}$ was ascribed to the symmetric $\mathrm{CH}_{2}$ bending vibration attributed to the crystalline cellulose. The peak at $1725 \mathrm{~cm}^{-1}$ was the characteristic $\mathrm{C}=\mathrm{O}$ peak stretching of carbonyl related to hemicellulose and lignin. While the peak at $1235 \mathrm{~cm}^{-1}$ was the characteristic peak of $\mathrm{C}-\mathrm{O}$ stretching of the aryl group in lignin. ${ }^{25}$ These peaks indicated that lignin and hemicelluloses existed in the untreated fiber specimens.

On the FTIR spectra of F1, the reduction of the peak at 1725 and $1235 \mathrm{~cm}^{-1}$ was observed and was attributed to the partial
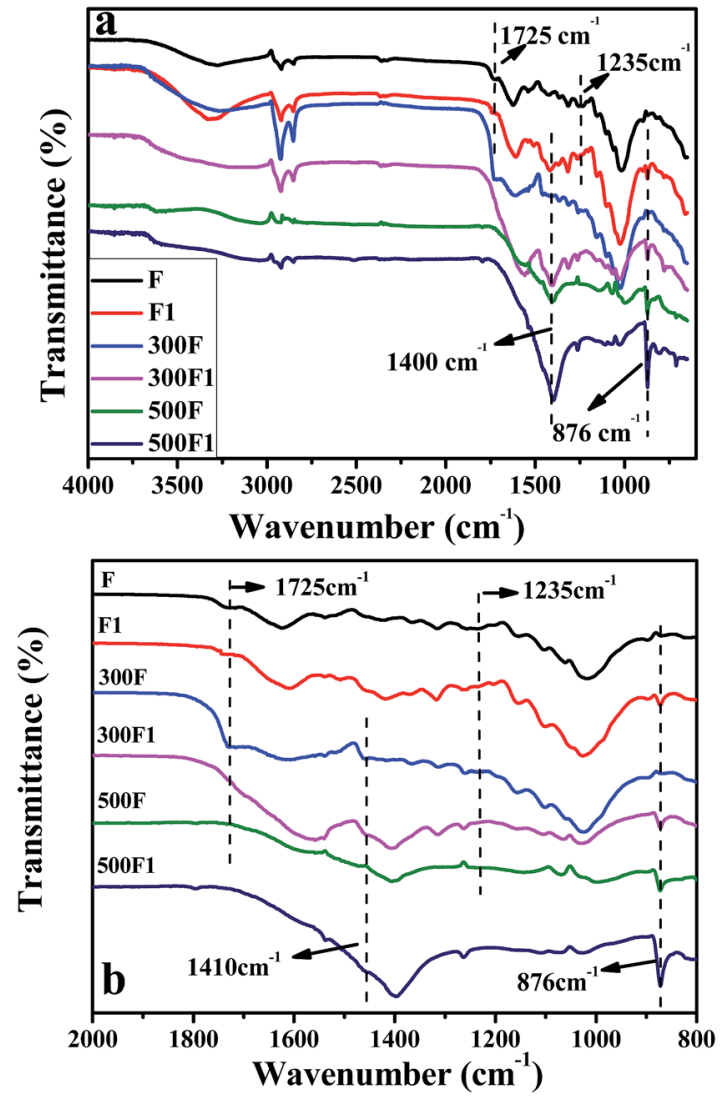

Fig. 1 FTIR spectra of the untreated hemp fiber $F$ and treated hemp fiber F1, the thermal degradation residue 300F, 300F1, 500F and 500F1 (a); the enlarged spectra range of $750-2500 \mathrm{~cm}^{-1}$ (b).

removal of lignin and hemicelluloses after modification. The removal of hemicellulose and lignin by alkali treatment caused the fibrils to rearrange themselves in a more compact manner and resulted in closer fiber packing, and thus the crystallinity of the fibers was also increased. This treatment thus could improve the fiber strength properties. In addition, the characteristic peak of the hydroxyl group improved after modification, as shown in Fig. 1. This improvement was due to the more hydroxyl groups exposed on the fiber surface after modification. ${ }^{26,27}$ Our treatment effect was similar with that of $\mathrm{NaOH}$ treatment from the FTIR result, which proved that an extra $\mathrm{NaOH}$ existed in the system, or the fresh $\mathrm{Ca}(\mathrm{OH})_{2}$ could also have the similar treatment effect on hemp as $\mathrm{NaOH}$. Furthermore, the peak at $1411 \mathrm{~cm}^{-1}$ on the spectra of treated hemp fiber increased, and the small peak at $873 \mathrm{~cm}^{-1}$ appeared for the FTIR spectra of F1. This proved the formation of calcium carbonate during treatment. ${ }^{28,29}$

When sodium hydroxide and calcium chloride were mixed together, calcium hydroxide $\left(\mathrm{Ca}(\mathrm{OH})_{2}\right)$ was immediately produced. The amount of $\mathrm{NaOH}$ and $\mathrm{CaCl}_{2}$ added to the weight equivalent in the system was designed to induce a reaction.

The obtained $\mathrm{Ca}(\mathrm{OH})_{2}$ could be slightly dissolved in the water. The hydroxyl group can react with $\mathrm{NaOH}$, and a negative oxygen ion $\left(-\mathrm{O}^{-}\right)$could be produced on the fiber surface. The free $\mathrm{OH}^{-}$from the dissolved $\mathrm{Ca}(\mathrm{OH})_{2}$ transferred into $\mathrm{NaOH}$ 
with $\mathrm{Na}^{+}$, and the produced $\mathrm{NaOH}$ reacted with the hydroxyl group on the hemp fiber into $-\mathrm{O}^{-} \mathrm{Na}^{+}$. However, the dissolved $\mathrm{Ca}(\mathrm{OH})_{2}$ may react with the hydroxyl group on the fiber and the $\mathrm{O}^{-}$was also produced. ${ }^{18,19}$ Thus, calcium alkoxide was formed and grafted on the fiber surface. To obtain the potential balance, $-\mathrm{O}^{-} \mathrm{Ca}^{2+}-\mathrm{OH}$ was formed. Thus, $-\mathrm{O}^{-} \mathrm{Na}^{+}$and $-\mathrm{O}^{-} \mathrm{Ca}^{2+}$ $\mathrm{OH}$ were produced on the fiber surface. The reaction scheme is shown in Scheme 1. During this process, the produced $\mathrm{Ca}(\mathrm{OH})_{2}$ was continuously consumed, and the dynamic equilibrium caused it to continue dissolving. The undissolved $\mathrm{Ca}(\mathrm{OH})_{2}$ was deposited on the fiber surface through hydrogen bond between the hydroxyl group and oxygen. Further, it could react with the $\mathrm{CO}_{2}$ in the air into calcium carbonate.

Morphology observation. Fig. 2 shows the morphology photographs of $\mathrm{F}$ and $\mathrm{F} 1$, as obtained via scanning electron microscopy (SEM). Thick layers of cuticle (composed of lignin and hemicellulose) on the hemp surface were observed, as shown in Fig. 2(a). Fig. 2(b) shows that the fiber surface was coated with a layer of wax-like materials, and solid particles were inconsistently dispersed on the surface. These granules should be the $\mathrm{Ca}(\mathrm{OH})_{2}$ and $\mathrm{CaCO}_{3}$ produced after modification, which could not be fully washed off by the cleaning process.

Flammability of hemp fiber. Inorganic hydroxide $\mathrm{Mg}(\mathrm{OH})_{2}$ and $\mathrm{Al}(\mathrm{OH})_{3}$ are applied as flame retardant for natural fiber composites. As one of the alkaline-earth metal hydroxides, $\mathrm{Ca}(\mathrm{OH})_{2}$ has seldom been applied as a fire retarder. In this study, $\mathrm{Ca}(\mathrm{OH})_{2}$ was freshly in situ prepared and applied to modify hemp.

The limiting oxygen index (LOI) of the treated and untreated hemp fiber is shown in Table 2. The LOI tests characterize the minimum oxygen concentration required to support combustion. The LOI of the treated fiber was 25.5 , which was obviously higher than that of the untreated fiber (20.5). This proved that our modification with the alkali and calcium chloride on the hemp can effectively improve the fire resistance of hemp. As shown in Scheme 1, after the modification, part of the produced calcium hydroxide $-\mathrm{O}^{-} \mathrm{Ca}^{2+}-\mathrm{OH}$ and calcium carbonate $\mathrm{CaCO}_{3}$ were deposited on the hemp fiber surface. During burning, $-\mathrm{O}^{-} \mathrm{Ca}^{2+}-\mathrm{OH}$ reacted with $\mathrm{CO}_{2}$, and $\mathrm{CaCO}_{3}$ was also produced. When $\mathrm{CaCO}_{3}$ was burned, calcium oxide $\mathrm{CaO}$ was created. ${ }^{21,30-32}$ The CaO produced was attached to the combustible surface, which can further prevent the combustion from spreading. $\mathrm{CaO}$ can also continue to absorb the gas and smoke produced from the incomplete combustion of the polymer. It can absorb the half-burnt molten residue. Thus, the combustion of the treated

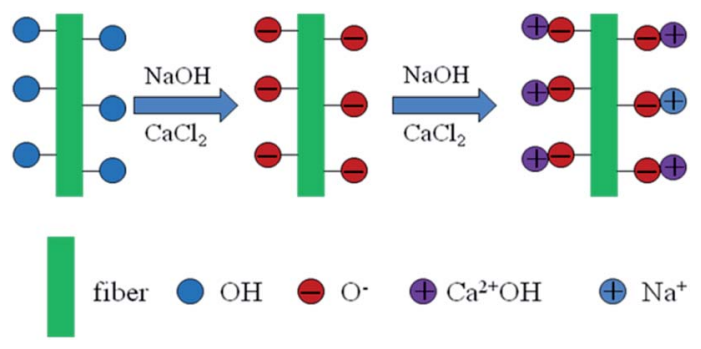

Scheme 1 Mechanism of the chemical treatment on the hemp.
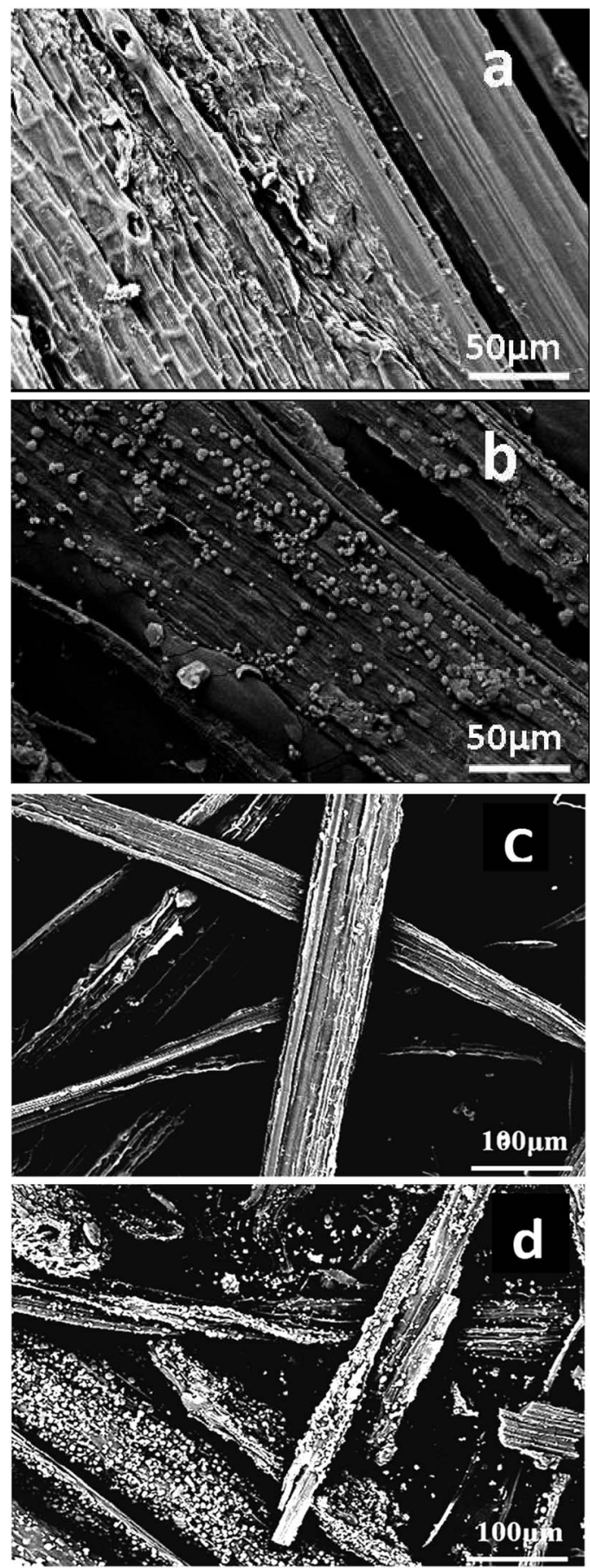

Fig. 2 SEM photos of the hemp fiber surface: (a) F; (b) F1, and the thermal degradation residue of hemp fiber surface: (c) 500F, (d) 500F1.

hemp stopped immediately, thereby eliminating the smoke and preventing droplets, and the LOI was significantly increased.

Thermal degradation residue of hemp. Fig. 1 shows the FTIR spectra of the thermal degradation residue of $\mathrm{F}$ and $\mathrm{F} 1$ heated at $300{ }^{\circ} \mathrm{C}$ and $500{ }^{\circ} \mathrm{C}$, respectively. Cellulose degrades at $300{ }^{\circ} \mathrm{C} \cdot{ }^{33,34}$ The characteristic peak of $-\mathrm{OH}$ at $3000 \mathrm{~cm}^{-1}$ to $3700 \mathrm{~cm}^{-1}$ weakened with the heating temperature, which proved that the hydroxyl group of calcium hydroxide, $-\mathrm{O}^{-} \mathrm{Ca}^{2+}-\mathrm{OH}$, and cellulose of hemp decreased with heating. The characteristic 
Table 2 Limiting oxygen index of the treated and untreated hemp and their reinforced composites

\begin{tabular}{lll}
\hline Samples & $\begin{array}{l}\text { Limiting oxygen } \\
\text { index }\end{array}$ & UL-94 \\
\hline Untreated hemp & 20.5 & - \\
Treated hemp & 25.5 & - \\
PP & 18.5 & - \\
PP-15R & 20.5 & - \\
PPF-20 & 19.3 & - \\
PPF-20-15R & 21.2 & - \\
PPF1-20 & 20.0 & - \\
PPF1-20-15R & 22.3 & - \\
PPF-30 & 20.5 & - \\
PPF-30-15R & 22.3 & - \\
PPF1-30 & 21.5 & - \\
PPF1-30-10R & 22.8 & - \\
PPF1-30-15R & 23.5 & - \\
PPF1-30-20R & 24.0 & - \\
PPF-50 & 22.3 & 0 \\
PPF-50-15R & 24.3 & - \\
PPF1-50 & 23.5 & 0 \\
PPF1-50-10R & 24.6 & 0 \\
PPF1-50-15R & 25.5 & 0 \\
PPF1-50-20R & 26.1 & \\
& &
\end{tabular}

peaks of $\mathrm{CaCO}_{3}$ were observed at $1400 \mathrm{~cm}^{-1}$ and $873 \mathrm{~cm}^{-1}$ for $300 \mathrm{~F} 1$ compared with that of $300 \mathrm{~F}^{29}$ The intensity of these peaks became more intensive compared with those of $\mathrm{F} 1$, as shown in Fig. 1. All attached $\mathrm{Ca}(\mathrm{OH})_{2}$ should react with $\mathrm{CO}_{2}$ during heating at $300{ }^{\circ} \mathrm{C}$ to produce $\mathrm{CaCO}_{3}$. Furthermore, the calcium alkoxide produced after modification also reacted with $\mathrm{CO}_{2}$ to produce $\mathrm{CaCO}_{3}$. These peaks appeared on the FTIR spectra of $500 \mathrm{~F}$ and $500 \mathrm{~F} 1$ with even higher intensity. The calcium salt component found in hemp may react with $\mathrm{CO}_{2}$ at $500{ }^{\circ} \mathrm{C}$ to produce $\mathrm{CaCO}_{3}$. The more $\mathrm{CaCO}_{3}$, the better flammability biocomposites present.

Fig. 3 shows the X-ray diffraction (XRD) patterns of thermal degradation residue of hemp produced at $500{ }^{\circ} \mathrm{C}$. The magnification figure in the region $30<2$ theta $<50$ degrees are inserted as Fig. 3(b) to better understand the data. The diffraction peaks of $500 \mathrm{~F}$ and $500 \mathrm{~F} 1$ were at $23.05^{\circ}, 29.4^{\circ}$, $36.12^{\circ}, 39.4^{\circ}, 43.12^{\circ}, 47.12^{\circ}$ and $48.54^{\circ}$. These are characteristic diffraction peaks of $\mathrm{CaCO}_{3}{ }^{21,29}$ The peak intensity of 500F1 spectra was higher than that of 500F. This is consistent with the result of FTIR characterization. The calcium salt in F1 was further proven to exist.

Fig. 2(c) and (d) show the SEM photos of the thermal degradation residue of $\mathrm{F}$ and $\mathrm{F} 1$, respectively, which also showed the existence of some white granules on the surface of $\mathrm{F} 1$ compared with that of $\mathrm{F}$ even at $500{ }^{\circ} \mathrm{C}$. The amount of white granules was much more than that on F1 as shown in Fig. 2(b). These white granules were determined to be $\mathrm{CaCO}_{3}$ through FTIR and XRD characterization, and proved the calcium alkoxide also transferred into $\mathrm{CaCO}_{3}$ during heating. When hemp was set on fire, thermal decomposition of $\mathrm{CaCO}_{3}$ occurred, thereby absorbing the heat on the burning surface and producing $\mathrm{CO}_{2}$ to stop the burning. Thus, hemp became

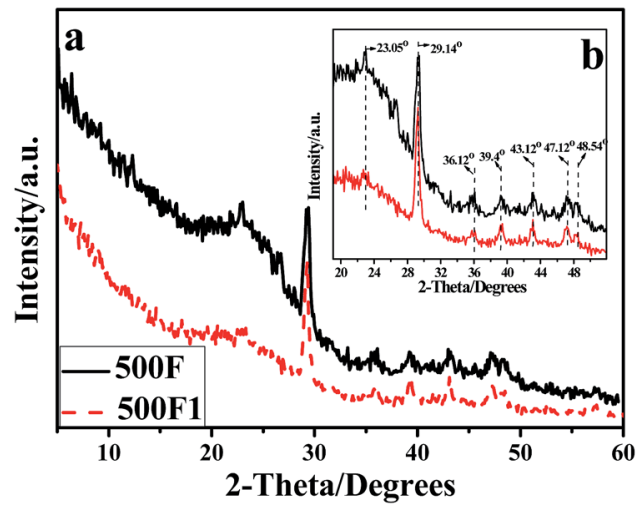

Fig. 3 WAXD curves of the 500F and 500F1 (a); the enlarged specta of the region $30<2$-theta $<50$ degrees (b).

a flame retardant after modification with in situ prepared calcium hydroxide.

\section{Performance of hemp/PP composites}

Flammability of PP composites. Table 2 and Fig. 4 shows the LOI value of PP and hemp/PP composites. The measurement result of UL-94 of the composites is also shown in Table 2. The LOI value of the composites was shown to be increased with the fiber ratio in the composites. The LOI of PPF-50 composite was 22.3 , which was much higher than that of pure PP $(\mathrm{LOI}=18.5)$. The reason should be that the hemp can behave as a type of char-forming agent, which can stop the burning from spreading and block oxygen. In addition, the LOI value of the modified hemp/PP composite was higher than that of the untreated hemp-reinforced composites. As an example, the LOI of PPF1-50 composite was 23.5. The fire resistance of our modified hemp reinforced PP composites could also be effectively improved, although PP is very flammable. To further improve the fire resistance of the composite, additional fire retardant, APP, was added to the composites. The LOI value of the composite with $20 \%$ hemp and $15 \%$ APP PPF-20-15R was 21.2, which was higher than that of PPF-20(19.3). And the LOI value of the composite increased with the APP content according to the comparison between the PP composite with $30 \%$ and $50 \%$ modified hemp

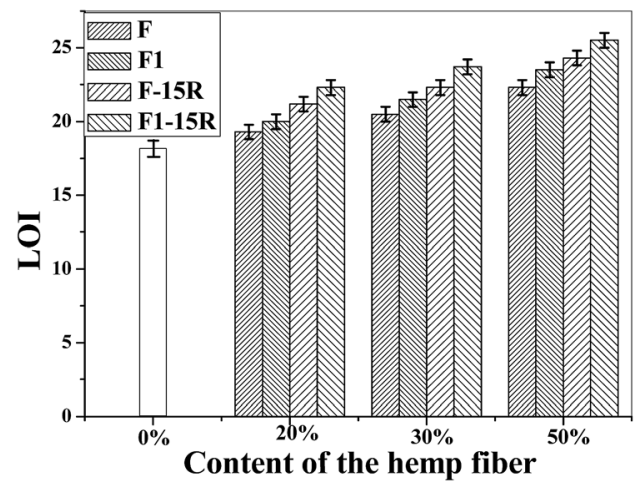

Fig. 4 Limiting oxygen index of the treated and untreated hemp and their reinforced composites. 
and different APP content, as shown in Table 2. The LOI value of the PP composite with 50\% modified hemp and 15\% APP PPF150-15R increased to 25.5. And the UL-94 measurement result of PPF-50-15R, PPF1-50-10R, PPF1-50-15R and PPF1-50-20R was 0. This means theses composites can self-extinguish when they are fired.

As an intumescent flame retardant, APP helped to introduce more residual char, and thus improve the fire retardancy of the composite. When the composites with APP were heated and began to decompose, ammonia and a very stable poly(phosphoric acid) were produced, and an insulating protective layer was formed on the material surface to block the oxygen for further burning. Therefore, the flammability resistance of composite was improved after adding APP. ${ }^{\mathbf{1 1 , 1 2 , 1 4 , 3 5}}$

The LOI value of PPF1-50-10R was 24.6, and it could also selfextinguish according to the UL-94 test result, which means $10 \%$ APP was good enough for the composite fire resistance when modified fiber was 50\%. For the better fire retardancy and low expenses of composites, PPF1-50-15R was applied for the further composite property study.

Mechanical properties. Many reports about the application of APP and inorganic hydroxides, such as $\mathrm{Mg}(\mathrm{OH})_{2}$ and $\mathrm{Al}(\mathrm{OH})_{3}$, on the flame retardant composites could be found.,13-15 The addition of a large amount of flame retardants to the composites could effectively improve the flammability of the composites. However, the mechanical properties of the composites were normally affected.

Fig. 5 shows the tensile strength (a) and modulus (b) of virgin PP and PP composites. Hemp fiber loading ratio in the composite was $0 \%, 20 \%, 30 \%$, and $50 \%$. The composite tensile strength and modulus increased with fiber loading ratio. When the hydrophilic hemp fiber was used to reinforce the hydrophobic polymer matrix, the poor compatibility between the natural fiber and polymer matrix usually result in bad mechanical properties. MAPP was reported to be a good compatibilizer for natural fiber/polymer composites. The mechanism is supposed to be the esterification between the anhydride groups of MAPP and the hydroxyl groups of the natural fiber.18,20 In this work, MAPP was applied in all the composite formulations for the best mechanical property. With MAPP, the tensile strength of composite with $20 \%$ of untreated hemp fiberreinforced PP composite (PPF-20) was 22.6 MPa, which was comparable with that of PP. Furthermore, the strength of the inorganic-modified hemp-reinforced composite PPF1-20 was 26.5 MPa. Both strength and modulus of PPF1-20 were much better than those of PPF-20. And similarly, PPF1-30 and PPF1-50 also presented better tensile properties than those of PPF-20 and PPF-20, respectively. The tensile strength of the composite reinforced with 50\% treated hemp fiber PPF1-50 increased to $38 \%$ compared with that of pure PP, while its modulus was three times that of PP.

The result proved that our inorganic modification on hemp fibers could help to improve the tensile properties of the composites, unlike the results of formal studies. ${ }^{6}$ The tensile strength and modulus of modified hemp reinforced composites increased more obviously with the modified hemp content than those of unmodified hemp reinforced composites increased
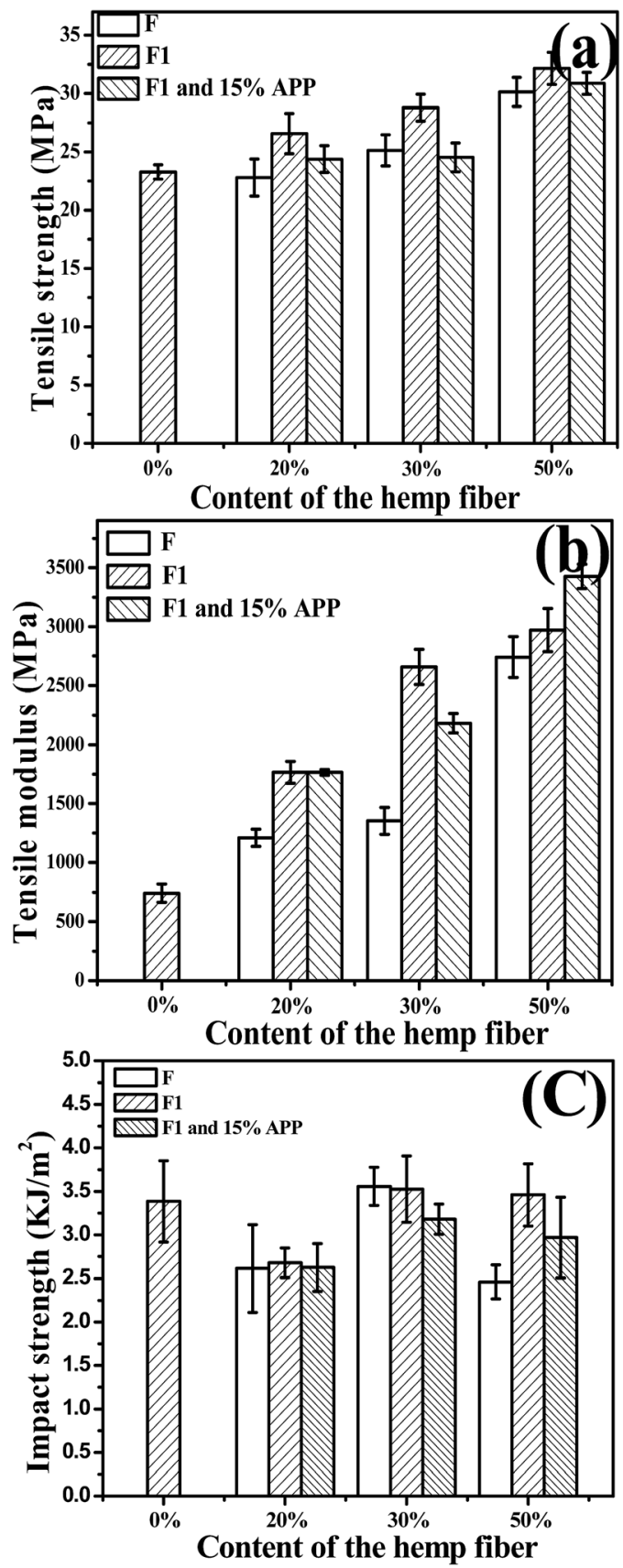

Fig. 5 Effect of hemp fiber loading ratio on the tensile strength (a), tensile modulus (b) of hemp fiber/PP composites and (c) impact strength.

with the unmodified hemp content. The hemp has the better stiffness than PP. On the other hand, the $-\mathrm{O}^{-} \mathrm{Ca}^{2+}-\mathrm{OH}$ produced on the fiber surface may also react with MAPP by the esterification between the anhydride groups of MAPP and the hydroxyl of the $-\mathrm{OCa}^{2+}-\mathrm{OH}$ on the natural fiber. The interfacial interaction and mechanical properties thus could be much improved.

However, the tensile strength of the composite compounded with treated hemp fiber and 15\% APP was always lower than that of composites without APP, although they were still higher 
than that of the pure PP. This result was caused by the APP insertion, which was supposed to be hydrophilic and likely to upset the interfacial adhesion between the fiber and matrix and thus the mechanical properties. Nevertheless, the modulus of the composites was not affected by the APP insertion as shown in Fig. 5(b). Instead, it increased with the APP insertion maybe because of the rigidity of APP.

Fig. 5(c) shows the impact strength of virgin PP and the composites. The composites with $30 \%$ of hemp presented a better impact strength compared with that of the other two contents, and it was also comparable with that of PP. Modification on the hemp did not seem to influence the impact strength of the composites obviously. However, APP insertion in the composites resulted in a worse impact strength of the composites, which revealed the poor interface compatibility between APP and PP.

Morphology observation. Fig. 6 shows the SEM photographs of fractured surfaces of the composite with 50\% hemp fiber and different formulation. Fig. 6(a) of untreated hemp fiber/PP composite PPF-50 shows that the interface was worse than that of PPF1-50 with the holes left by the pulled-out fibers. Fibers were pulled out from the matrix during the fracture process, indicating poor interfacial interaction between hemp fiber and PP matrix which resulted in poor composite mechanical properties. ${ }^{36}$ Fig. 6(b) of PPF1-50 showed the better interfacial adhesion between modified hemp and PP. Fibers were even split by the fracture before they were pulled out from the matrix, which proved the stronger composite interface. This led to a composite material with excellent mechanical properties. However, the composite interface was the worst with APP insertion (PPF1-50-15R), as shown in Fig. 6(c), in the light that the cracks between the fiber and matrix and the APP powder could be obviously observed. APP aggregation also existed in the matrix and the interface. These resulted in the bad mechanical properties of the composites.

Crystallization behaviour. Table 3 shows the crystallization temperature $\left(T_{\mathrm{c}}\right)$, melting temperature $\left(T_{\mathrm{m}}\right)$, melting enthalpy $\left(\Delta H_{\mathrm{m}}\right)$, and the degree of crystallinity $\left(X_{\mathrm{c}}\right)$ of the composites obtained from the differential scanning calorimetry (DSC) analysis.

The DSC results showed that the crystallization temperature $T_{\mathrm{c}}$ of all the composites was lower than that of $\mathrm{PP}\left(122^{\circ} \mathrm{C}\right)$. The hemp insertion promoted the nucleation and crystallization of $\mathrm{PP}$, and thus lowered the $T_{\mathrm{c}}$ of PP to approximately $112{ }^{\circ} \mathrm{C} . T_{\mathrm{c}}$ did not vary with the hemp content apparently. However, $T_{\mathrm{c}}$ of the PPF1 series composites was higher than that of PPF series composites. The modified hemp presented less nucleation effect on PP. The APP insertion did not further decrease the $T_{\mathrm{c}}$ of the untreated hemp fiber-reinforced composites.

The crystallization of composites is controlled by two factors. The reinforcements presented a nucleating effect that caused the crystallization temperature and degree of crystallization to increase. However, the reinforcement restricted the migration and diffusion of polymer chains to the growing polymer crystal in the composites. Thus, the crystallization temperature decreased with the reinforcements because of its negative effect on crystallization. ${ }^{37,38}$ In our study, the $T_{\mathrm{c}}$ of all the composites
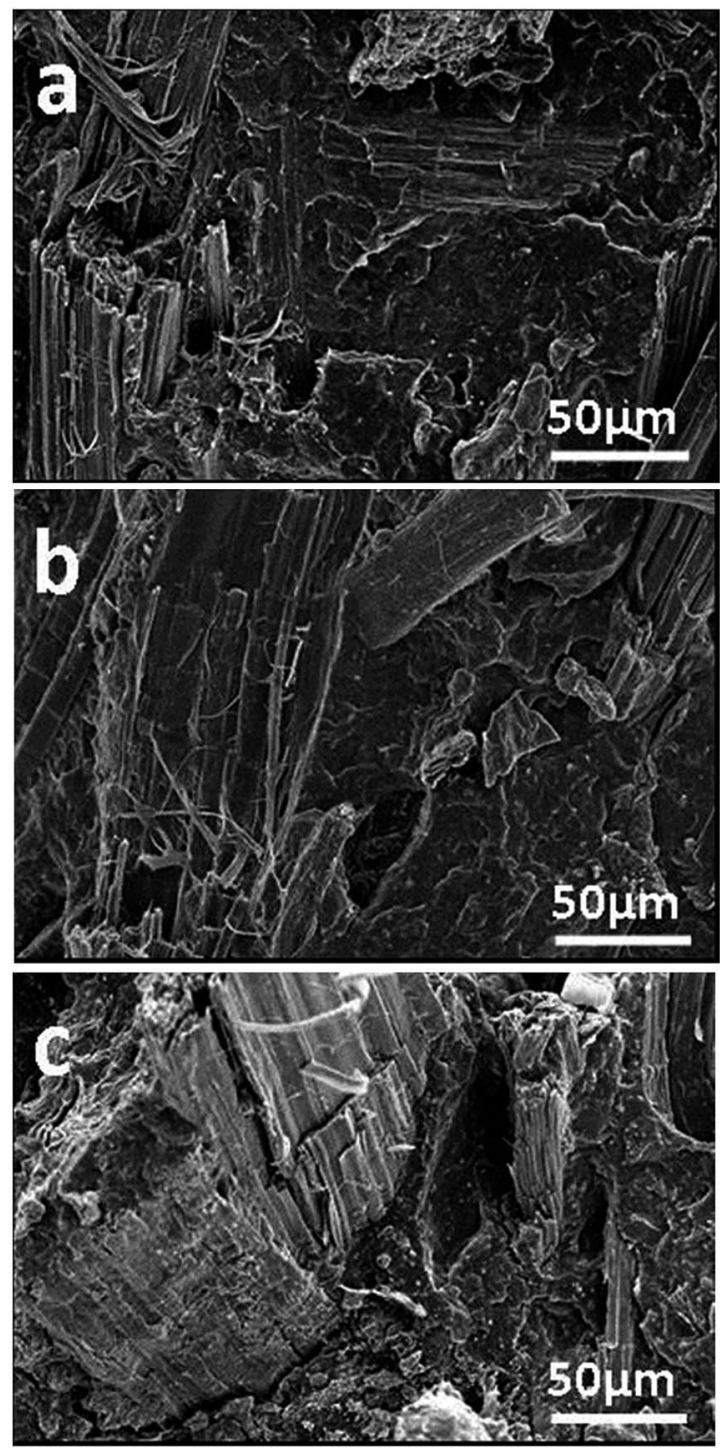

Fig. 6 SEM photos of the fractured composite surface: (a) PPF-50, (b) PPF1-50, (c) PPF1-50-15R composite.

decreased, which should be related to the addition of the hemp and APP. The hemp fibers and APP hindered the migration and diffusion of PP chains to the crystal nucleus in the composites.

The melting temperature $\left(T_{\mathrm{m}}\right)$ of the composites was not much different from that of PP and did not change obviously with the composite formulation, as shown in Table 3. This showed that the feature of the crystal formed during the crystallization was not significantly influenced by the hemp and APP insertion.

The XRD curves of hemp fiber reinforced PP composite and pure $P P$ are shown in Fig. 7. The characterized diffraction peaks of pure PP at $2 \theta=13.7^{\circ}, 16.6^{\circ}, 18.3^{\circ}, 21.5^{\circ}$ and $25.2^{\circ}$ was correspond to the monoclinic alpha-phase with planes (110), (040), (130), (041), and (060). ${ }^{39}$ The diffraction curves of all the composites also presented the same diffraction peak position with those of PP, which also proved the insertion of hemp and APP did not change the crystallization behavior of PP. However, 
Table 3 Thermal and crystallization properties of PP and the composites

\begin{tabular}{|c|c|c|c|c|c|c|c|}
\hline Samples & $T_{\mathrm{c}}\left({ }^{\circ} \mathrm{C}\right)$ & $T_{\mathrm{m}}\left({ }^{\circ} \mathrm{C}\right)$ & $\Delta H_{\mathrm{m}}\left(\mathrm{J} \mathrm{g}^{-1}\right)$ & $X_{\mathrm{c}}(\%)$ & $T_{5}\left({ }^{\circ} \mathrm{C}\right)$ & $T_{10}\left({ }^{\circ} \mathrm{C}\right)$ & $T_{50}\left({ }^{\circ} \mathrm{C}\right)$ \\
\hline PP & 122 & 151 & 68.76 & 33.4 & 431 & 445 & 474 \\
\hline PPF-20 & 110 & 147 & 52.93 & 32.1 & 357 & 390 & 474 \\
\hline PPF1-20 & 119 & 150 & 47.59 & 28.8 & 339 & 379 & 486 \\
\hline PPF1-20-15R & 111 & 148 & 43.43 & 32.5 & 305 & 368 & 482 \\
\hline PPF-30 & 112 & 148 & 42.81 & 29.7 & 327 & 356 & 471 \\
\hline PPF1-30 & 119 & 150 & 47.44 & 32.9 & 291 & 340 & 478 \\
\hline PPF1-30-15R & 113 & 149 & 40.91 & 36.2 & 284 & 325 & 483 \\
\hline PPF-50 & 112 & 148 & 32.54 & 31.8 & 309 & 345 & 469 \\
\hline PPF1-50 & 118 & 149 & 35.25 & 34.4 & 265 & 296 & 481 \\
\hline PPF1-50-15R & 113 & 148 & 21.37 & 30.1 & 265 & 295 & 489 \\
\hline
\end{tabular}

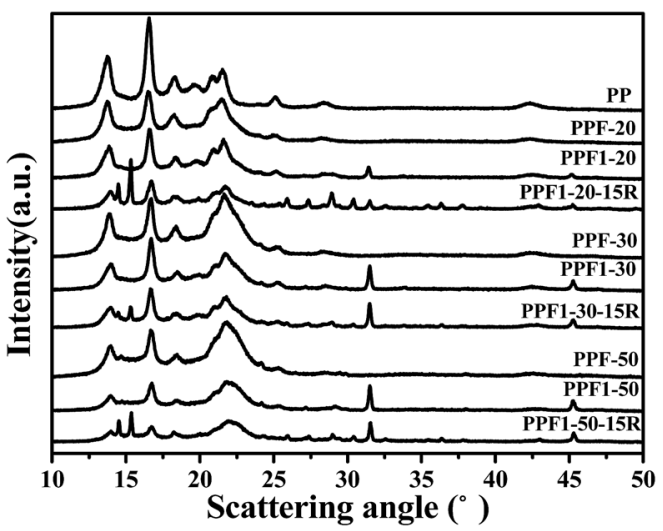

Fig. 7 XRD curves of hemp fiber/PP composite and pure PP.

the intensity of the peaks decreased for the composites with hemp and APP insertion. This means the crystallinity of PP decreased as shown in Table 3, which may be due to the hemp and APP restricting the PP crystallization and the crystal growth.

The diffraction peaks on the curves of PPF1 series at $2 \theta=$ $31.4^{\circ}$ and $45.2^{\circ}$ were due to the $\mathrm{Ca}(\mathrm{OH})_{2}$ that was produced and attached on the fiber surface during modification. ${ }^{40,41}$ When $\mathrm{Ca}(\mathrm{OH})_{2}$ was exposed in the air, $\mathrm{CaCO}_{3}$ was generated. The diffraction peaks on the curves of PPF1-15R series appeared at $2 \theta=14.5^{\circ}$ and $15.3^{\circ}$ was ascribed to be the diffraction peaks of APP. ${ }^{42}$ The other small peaks appearing on the curves of APPinserted composites are brought about by the impurities in the commercial APP.

Thermal stability. Fig. $8($ a) shows the thermogravimetric analysis (TGA) thermograms of PP and its composites. The first decomposition occurred in the temperature range of $230{ }^{\circ} \mathrm{C}$ to $370^{\circ} \mathrm{C}$ indicating the decomposition of hemp fiber and APP, the decomposition of the matrix occurred in the temperature range between $380^{\circ} \mathrm{C}$ and $510{ }^{\circ} \mathrm{C} .{ }^{14,15}$

Table 3 shows the TGA analysis results, including $5 \%$ weight loss temperature $\left(T_{5}\right)$ and $10 \%$ weight loss temperature $\left(T_{10}\right)$ of PP and composites. All the $T_{5}$ of the composites decreased with the increasing fiber content, and the $T_{5}$ of the composites were lower than that of the pure PP. This is because of the low thermal stability of the hemicelluloses in hemp. ${ }^{16}$ The $T_{5}$ value of PPF series of composites were the highest, the PPF1-R series of composites were the lowest. This may be caused by the $\mathrm{Ca}^{2+}$
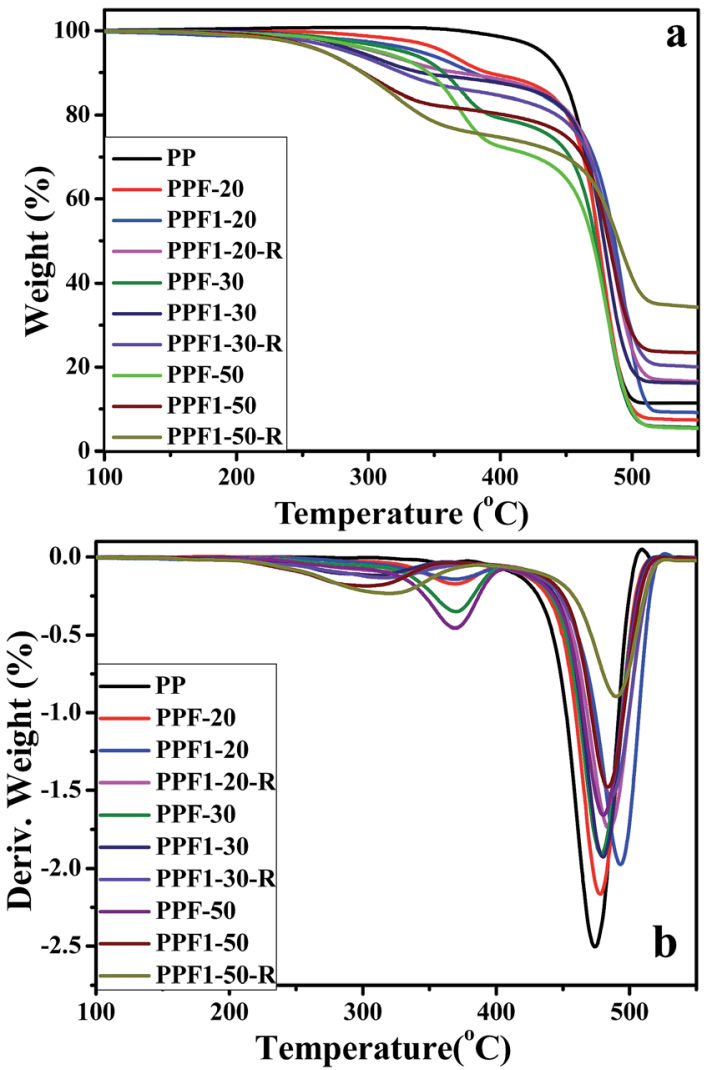

Fig. 8 (a) TGA thermograms of pure PP and the composites; (b) DTG curves of pure PP and the composites.

on the surface of the $\mathrm{F} 1$ which could promote the thermal degradation of the hemp fiber to produce $\mathrm{CaCO}_{3}$. The thermal stability of PPF1-R series composites were poor, this may be because the APP releases acid and non-flammable gases when exposed to high temperature; these acids contribute to hemp fiber dehydration and charring. ${ }^{15}$ Furthermore, all the $T_{5}$ of composites were still higher than $250^{\circ} \mathrm{C}$. This thermal stability of the hemp-reinforced PP composites was good enough for their application in many fields, such as packaging, construction and automotive interiors.

Fig. 8(b) shows the derivative thermogravimetric analysis (DTG) curves of pure PP and composites. Two peaks with maxima ranging between $300{ }^{\circ} \mathrm{C}$ to $370{ }^{\circ} \mathrm{C}$ and $470{ }^{\circ} \mathrm{C}$ to $490{ }^{\circ} \mathrm{C}$ 
were observed for the composites. The temperature with the maximum degradation speed $\left(T_{\max }\right)$ of PP and composites is shown in Table 3. $T_{\max }$ increased slightly with the hemp and APP content, which should be related to the high thermal stability of inorganic chemicals.

\section{Conclusions}

In this study, the flammability of hemp fiber was improved by the in situ treatment of the mixture of $\mathrm{NaOH}$ and $\mathrm{CaCl}_{2}$. Calcium alkoxide was produced on the surface of fiber with the treatment, and calcium hydroxide and the calcium carbonate were thereafter absorbed on the fiber surface, which should be helpful in the improvement of the fire retardancy. Thereafter, the flammability of the composites was also improved, and was further improved by APP insertion. The LOI of the PPF1-50 was 23.5 , which was much higher than that of PP of $18.5 \%$. When the APP was added, the flammability of the composite was improved by synergistic interaction between freshly produced calcium hydroxide and APP. The LOI of the PPF1-50-15R was increased to 25.5. Furthermore, the comprehensive mechanical properties of composite materials were also much improved according to the mechanical property characterization. The tensile strength of the PPF1-50 composite was increased by $38 \%$ compared with that of pure PP. The thermal stability of the hemp fiber/PP composites demonstrated by $T_{5}$ was higher than $250{ }^{\circ} \mathrm{C}$, and could be applied in many fields, such as packaging, construction and automotive interiors. XRD characterization proved that calcium salt was produced with the treatment. The XRD and DSC results proved the treated hemp did not apparently change the crystal feature of PP. In other words, the inorganic flame retardant-treated hemp can be applied as a reinforcement for flame retardant biocomposites with excellent properties.

\section{Acknowledgements}

The authors would like to thank to the financial support for this project from the National Natural Science Foundation of China (No. 21404013), the Science and Technology Development Plan of Jilin Province, China (No. 20140204039GX and No. 20160101323JC), Changchun Science and Technology Plan Project, China (No. 14KG105), Open Research Fund of State Key Laboratory of Polymer Physics and Chemistry, Changchun Institute of Applied Chemistry, Chinese Academy of Sciences, and the Research Project of Science and Technology of the Education Department of Jilin Province during the 12th Fiveyear Plan Period (No. 2015-78).

\section{References}

1 S. Duquesne, F. Samyn, P. Ouagne and S. Bourbigot, J. Ind. Text., 2015, 44(5), 665-681.

2 J. T. Kim and A. N. Netravali, Agric. Food Chem., 2010, 58, 5400-5407.

3 S. A. Paul, K. Joseph, G. Mathew, L. A. Pothen and S. Thomas, Polym. Compos., 2010, 31, 816-824.
4 T. J. Madera-Santana, H. S. Valdez and M. O. W. Richardson, Polym. Eng. Sci., 2013, 53, 59-68.

5 L. B. Manfredi, E. S. Rodriguez, M. Wladyka-Przybylak and A. Vazquez, Polym. Degrad. Stab., 2006, 91, 255-261.

6 N. Suppakarn and K. Jarukumjorn, Composites, Part B, 2009, 40, 613-618.

7 S. L. Du, X. B. Lin, R. K. Jian, C. Deng and Y. Z. Wang, Chin. J. Polym. Sci., 2015, 33(1), 84-94.

8 M. W. Chai, S. Bickerton, D. Bhattacharyya and R. Das, Composites, Part B, 2012, 43, 2867-2874.

9 A. Rachini, G. Mougin, S. Delalande, J. Y. Charmeau, C. Barres and E. Fleury, Polym. Degrad. Stab., 2013, 97, 1988-1995.

10 R. Kozlowski and M. Wladyka-Przybylak, Polym. Adv. Technol., 2008, 19, 446-453.

11 F. Shukor, A. Hassan, S. M. Islam, M. Mokhtar and M. Hasan, Mater. Des., 2014, 54, 425-429.

12 R. Jeencham, N. Suppakam and K. Jarukumjor, Composites, Part B, 2014, 56, 249-253.

13 A. Subasinghe and D. Bhattacharyya, Composites, Part A, 2014, 65, 91-99.

14 Y. H. Guan, W. Liao, Z. Z. Xu, M. J. Chen and J. Q. Huang, RSC Adv., 2015, 5, 59865-59873.

15 J. Z. Liang and Y. J. Zhang, Polym. Int., 2010, 59, 539-542.

16 M. Sain, S. H. Park, F. Suhara and S. Law, Polym. Degrad. Stab., 2004, 83, 363-367.

17 A. A. Bakar and N. Baharulrazi, Polym.-Plast. Technol. Eng., 2008, 47, 1072-1079.

18 X. Li, L. G. Tabil and S. Panigrahi, J. Polym. Environ., 2007, 15, 25-33.

19 A. K. Mohanty, M. Misra and L. T. Drzal, Compos. Interfaces, 2001, 8(5), 313-343.

20 A. E. Sabbagh, Composites, Part B, 2014, 57, 126-135.

21 Marwan and E. Indarti, Energy Convers. Manage., 2016, 117, 319-325.

22 M. C. Yew, N. H. Ramli Sulong, M. K. Yew, M. A. Amalina and M. R. Johan, Prog. Org. Coat., 2015, 78, 59-66.

23 R. N. Rothon and P. R. Hornsby, Polym. Degrad. Stab., 1996, 54, 383-385.

24 M. R. Islam, M. Rivai, A. Gupta and M. D. H. Beg, J. Polym. Eng., 2015, 35(2), 135-143.

25 H. Sosiati and Harsojo, Cellul. Chem. Technol., 2014, 48, 33-43. 26 K. O. Reddy, C. U. Maheswari, M. Shukla, J. I. Song and A. V. Rajulu, Composites, Part B, 2013, 44, 433-438.

27 D. Ray, B. K. Sarkar, A. K. Rana and N. R. Bose, Composites, Part A, 2001, 32, 119-127.

28 M. Chabannes, E. Garcia-Diaz, L. Clerc and J. C. Bénézet, Constr. Build. Mater., 2016, 102, 821-833.

29 L. X. Bao, S. M. Yang, X. Luo, J. X. Lei, Q. Cao and J. L. Wang, Appl. Surf. Sci., 2015, 357, 564-572.

30 A. E. F. S. Almeida, G. H. D. Tonoli, S. F. Santos and H. Savastano Jr, Cem. Concr. Compos., 2013, 42, 49-58.

31 V. D. Pizzol, L. M. Mendes, L. Frezzatti, H. Savastano Jr and G. H. D. Tonoli, Miner. Eng., 2014, 59, 101-106.

32 G. H. D. Tonoli, V. D. Pizzol, G. Urrea, S. F. Santos, L. M. Mendes, V. Santos, V. M. John, M. Frías and H. Savastano Jr, J. Mater. Sci., 2016, 51, 7929-7943. 
33 S. S. L. Sobhana, D. R. Bogati, M. Reza, J. Gustafsson and P. Fardim, Microporous Mesoporous Mater., 2016, 225, 66-73. 34 C. Quan, N. B. Gao and Q. B. Song, J. Anal. Appl. Pyrolysis, 2016, 121, 84-92.

35 F. Samyn, S. Bourbigot, S. Duquesne and R. Delobel, Thermochim. Acta, 2007, 456, 134-144.

36 P. Sudhakara, A. P. K. Devi, C. V. Prasad, K. O. Reddy, L. D. Woo, B. S. Kim and J. I. Song, J. Appl. Polym. Sci., 2013, 128, 976-982.
37 M. S. Huda, L. T. Drzal, M. Misra, A. K. Mohanty, K. Williams and D. F. Mielewski, Ind. Eng. Chem. Res., 2005, 44, 55935601.

38 C. Albano, J. Papa, M. Ichazo, J. Gonzalez and C. Ustariz, Compos Struct., 2003, 62, 291-302.

39 F. Adam and M. S. Wong, Catal. Commun., 2011, 13, 87-90.

40 M. I. Zaki, H. Knozinger, B. Tesche and G. A. H. Mekhemer, J. Colloid Interface Sci., 2006, 303, 9-17.

41 H. J. Lin, H. Yan, B. Liu, L. Q. Wei and B. S. Xu, Polym. Degrad. Stab., 2011, 96, 1382-1388. 